\title{
Aproveitamento de soro lácteo na formulação de bebidas com frutas e hortaliças
}

\author{
[The use of whey in the formulation of beverages with fruits and vegetables] \\ A.F.L.M. Guedes ${ }^{1}$, E.C.L. Machado ${ }^{2}$, M.C. Fonseca ${ }^{3}$, S.A.C. Andrade ${ }^{2}$, T.L.M. Stamford ${ }^{2}$ \\ ${ }^{1}$ Aluno de pós-graduação - Universidade Federal de Pernambuco - Recife, PE \\ ${ }^{2}$ Universidade Federal de Pernambuco - Recife, PE \\ ${ }^{3}$ Nutricionista autônoma \\ RESUMO
}

\begin{abstract}
O uso do soro lácteo como complemento na formulação de alimentos visando ao seu aproveitamento é uma alternativa para a obtenção de novos produtos. Neste trabalho, desenvolveram-se bebidas à base de soro oriundo de queijo coalho tipo A com frutas e hortaliças. Na formulação das bebidas, utilizaram-se diferentes proporções entre soro lácteo, frutas e hortaliças, com adição de $10 \%$ de açúcar. Seis bebidas foram formuladas e submetidas a um teste de preferência, e as três primeiras colocadas foram submetidas a um teste de aceitação sensorial. As três preferidas foram as bebidas sabor graviola, morango e goiaba. A bebida sabor graviola obteve aceitação com as melhores notas nos atributos sensoriais cor, sabor, aparência e qualidade global, seguida pela formulação de sabor morango, mas sem diferença significativa $(\mathrm{P}>0,05)$. A bebida sabor goiaba teve o diferencial no atributo odor e superou as bebidas sabor graviola e morango $(\mathrm{P}<0,05)$. Conclui-se que é viável a elaboração de bebidas à base de soro de queijo coalho com frutas.
\end{abstract}

Palavras-chaves: soro de queijo coalho, graviola, hortelã, cenoura

\begin{abstract}
The use of whey as complement in food formulation aiming it's an alternative for the attainment of new products. The aim of this work was developed a type A curd cheese whey derived drink with fruits and vegetables. On drink's formulation was used different ratios of whey, fruits and vegetables, with $10 \%$ of sugar. Six drinks were formulated and submited to a preference test. The three best drinks were submitted to a acceptance test. The three best drinks were graviola, strawberry and guava flavours. The graviola one had the greater acceptability with best grades in color's sensory attributes, flavor, appearance and overall quality, following the strawberry flavor, but without significant difference $(P<0,05)$. The guava dink had it's differential on scent character, overcoming the graviola and strawberry drinks $(P<0,05)$. In conclusion we can say that whey-based drink with fruits is viable.
\end{abstract}

Keywords: whey cheese curds, soursop, mint, carrot

\section{INTRODUÇÃO}

Estima-se que em 2011 o Brasil produza mais de 32 bilhões de litros de leite de vaca, com 28 bilhões de litros consumidos e 1,10 bilhões de litros exportados (Mapa, 2010). O Nordeste é responsável por $12 \%$ de todo o leite produzido no país, e o estado de Pernambuco ocupa o oitavo lugar no cenário nacional, com produção

Recebido em 26 de novembro de 2011

Aceito em 4 de dezembro de 2012

E-mail: andrei.loureiro@gmail.com de 725.786.000 de litros de leite ao ano (IBGE, 2009).

As indústrias de pequeno porte e os pequenos produtores enfrentam dificuldades com o excedente do soro do leite, subproduto resultante da transformação do leite em queijos por coagulação enzimática da caseína ou por adição de ácido, de forma que, em sua grande maioria, optam pelo descarte do produto diretamente na 
rede pública, em rios e lagos, acarretando, para cada tonelada de soro não tratado despejado, poluição diária de material orgânico equivalente a cerca de 470 pessoas, visto que possui demanda bioquímica de oxigênio (DBO) entre 30.000 e $60.000 \mathrm{mg}$ de $0_{2}$ por litro (Andrade e Martins, 2002).

A conversão do soro de queijo em outros produtos tem se mostrado uma boa alternativa para que o descarte no meio ambiente seja evitado, além do que o soro possui ainda valor nutricional, incluindo lactose, minerais, vitaminas e proteínas (Capitani et al., 2005). Aliada às características nutricionais do soro lácteo, a procura do consumidor brasileiro por produtos mais saudáveis, inovadores, seguros e de utilização prática tem contribuído para o crescimento da produção das bebidas lácteas. Esse produto vem ganhando mercado, principalmente pelo conhecimento da população sobre o teor de cálcio (Santos e Ferreira, 2001).

A produção de bebida láctea no Brasil tem se tornado uma das principais opções de aproveitamento do soro de leite a baixo custo e com facilidade de processamento por ser possível o uso dos equipamentos já existentes na indústria (Pintado et al., 2001). A possibilidade de mistura do soro de queijo com frutas e/ou hortaliças para a obtenção de bebidas, produtos lácteos, sopas e sobremesas teria como benefício um produto constituído de fibras, vitaminas e sais minerais, sendo uma alternativa na composição de dietas de grupos institucionais - asilos, hospitais, creches, merenda escolar, entre outros - além de atender à demanda do mercado por uma variedade maior de produtos dessa natureza.

Este trabalho teve por objetivo avaliar o aproveitamento do soro lácteo oriundo da fabricação de queijo coalho na elaboração de bebidas com frutas e hortaliças.

\section{MATERIAL E MÉTODOS}

Os soros de queijo coalho tipo A foram cedidos por uma indústria de laticínios localizada no agreste de Pernambuco, sendo coletados diretamente do tanque de produção, em recipientes higienizados e transportados em caixa isotérmica. $\mathrm{O}$ soro lácteo previamente pasteurizado à temperatura de $65^{\circ} \mathrm{C}$ por $30 \mathrm{~min}$ foi submetido à homogeneização com polpa de fruta, extrato de hortaliça e açúcar. Foram utilizados os soros que obtiveram resultados satisfatórios nas análises microbiológicas para a formulação de seis tipos de bebidas: A - morango $(50 \%)$ + soro $(50 \%)$; B - caju $(65 \%)+$ soro $(35 \%) ; \mathrm{C}-$ goiaba $(35 \%)+$ soro $(65 \%) ; \mathrm{D}-$ graviola $(35 \%)+$ soro $(65 \%)$; E - acerola $(45 \%)+$ cenoura $(10 \%)+$ soro $(45 \%) ; \mathrm{F}$ - abacaxi $(24 \%)+$ hortelã $(0,5 \%)+$ soro $(75 \%)$, sendo a adição de açúcar na quantidade de $10 \%$ e, em seguida, as bebidas foram mantidas sob refrigeração $\left(8^{\circ} \mathrm{C}\right)$.

Para obtenção da polpa de frutas, foram seguidas as etapas: seleção, lavagem com água corrente, sanitização com solução de água clorada a 20ppm, despolpamento, e pesagem. Para a obtenção do extrato das hortaliças, realizaram-se os seguintes procedimentos: seleção, lavagem em água corrente, sanitização com solução de água clorada a 20ppm, obtenção do extrato em extrator (centrífuga PRO 2, Britânia) e pesagem.

No soro lácteo, foram realizadas análises físicoquímicas: $\mathrm{pH}$, acidez total titulável, proteínas (método de Kjeldahl), lipídeos (método de Gerber), umidade (método termogravimétrico em estufa a $105^{\circ} \mathrm{C}$ ) e minerais (método termogravimétrico em mufla a $550^{\circ} \mathrm{C}$ ) (Association..., 2002). Para os ensaios microbiológicos, os parâmetros utilizados foram os mesmos realizados para o queijo coalho, como prevê a RDC $n^{\circ} 12$ da Agência Nacional de Vigilância Sanitária (BRASIL, 2001): contagem de coliformes termotolerantes a $45^{\circ} \mathrm{C}$ e Staphylococcus aureus, pelo método rápido utilizando placas petrifilm 3M (Association..., 2002). Para pesquisa de Salmonella, foi utilizado kit VIDAS - ICS (Vitek Immuno), e para Listeria monocytogenes, foi realizada contagem de células viáveis em meio de cultivo padrão (Vanderzant e Splittstoesser, 1992).

Das bebidas elaboradas, submetidas a um teste de ordenação de preferência, foram escolhidas as três primeiras. Os dados foram avaliados pela tabela de Newell e MacFairlene. Com as três, foi realizado teste de aceitabilidade utilizando-se a escala hedônica de nove pontos: 1 para desgostei extremamente e 9 para gostei extremamente. As amostras foram apresentadas a um painel sensorial de 50 provadores não treinados, entre alunos e professores da Universidade Federal de Pernambuco, de forma aleatória e codificadas. 
Foi calculado o índice de aceitabilidade (IA) de acordo com a expressão: IA $(\%)=$ A x 100/B, em que A é a nota média obtida para o produto e B é a nota máxima dada ao produto, sendo considerado IA com boa repercussão $\geq$ a $70 \%$ (Monteiro, 1984; Dutcosky, 1996). A nota 9, máxima, correspondeu a $100 \%$ de aceitabilidade, e avaliou-se o coeficiente de variação para definir a magnitude de dispersão entre os dados encontrados (Teixeira et al., 1987). Os dados foram avaliados pela ANOVA, utilizando-se teste de Duncan para comparação de médias a $5 \%$ de significância. Para verificar as relações entre os produtos obtidos e os atributos sensoriais, foi realizada a análise de componente principal, utilizando-se o programa "Statistic for windows" (Statsoft , 1997).

A bebida que apresentou o melhor resultado nas análises sensoriais foi submetida à análise de $\mathrm{pH}$, acidez titulável, proteínas - método de Kjeldahl -, lipídeos - método de Bligh Dyer -, umidade método gravimétrico em estufa a $105^{\circ} \mathrm{C}-$, e minerais - método gravimétrico em mufla a $550^{\circ} \mathrm{C}$ (Association..., 2002).

O projeto foi aprovado pelo Comitê de Ética em Pesquisa do Centro de Ciências da Saúde da UFPE, sob protocolo $\mathrm{n}^{\mathrm{o}} 321 / 08$ e todos os provadores participantes assinaram o termo de consentimento.

\section{RESULTADOS E DISCUSSÃO}

Os resultados das análises físico-químicas do soro lácteo estão apresentados na Tab. 1. Os valores de $\mathrm{pH}(6,44)$, proteínas $(0,73 \%)$, lactose $(3,64 \%)$, umidade $(92,68 \%)$, cinzas $(0,56 \%)$ e teor lipídico $(0,39 \%)$ são semelhantes aos encontrados por Teixeira e Fonseca (2008), que avaliaram o perfil físico-químico de soro lácteo obtido de queijo muçarela e minas-padrão no estado de Minas Gerais. Dessa forma, mesmo o soro lácteo não apresentando legislação vigente que determine seus parâmetros físico-químicos e microbiológicos, observa-se que a composição desses soros lácteos oriundos de diferentes tipos de queijos e regiões são semelhantes aos encontrados nesta pesquisa.
Tabela 1. Resultados das análises físico-químicas do soro de queijo coalho

\begin{tabular}{lc}
$\begin{array}{l}\text { Constituinte } \\
(\mathrm{g} / 100 \mathrm{~g})\end{array}$ & $\begin{array}{c}\text { Soro de queijo coalho } \\
(\text { Média } \pm \mathrm{DP})\end{array}$ \\
\hline Umidade & $92,68 \pm 0,54$ \\
$\mathrm{pH}$ & $6,44 \pm 0,10$ \\
Acidez & $0,70 \pm 0,37$ \\
Lipídeos & $0,39 \pm 0,25$ \\
Proteínas & $0,73 \pm 0,16$ \\
Lactose & $3,64 \pm 0,27$ \\
Cinzas & $0,56 \pm 0,03$ \\
\hline
\end{tabular}

Para os ensaios microbiológicos, os resultados mostram que Listeria monocytogenes e Salmonella spp. estavam ausentes em todas as amostras, enquanto para coliformes a $45^{\circ} \mathrm{C}$ as amostras apresentaram contagem que variou de 2,3 a $1.100 \mathrm{NMP} / \mathrm{mL}$ e para Staphylococcus coagulase positiva todas apresentaram contagem $<10 \mathrm{UFC} / \mathrm{mL}$. Estes resultados diferem dos encontrados por Teixeira et al. (2007) para $S$. aureus e coliformes a $45^{\circ} \mathrm{C}$, os quais avaliaram microbiologicamente os soros de queijo muçarela e minas-padrão em Minas Gerais, e encontraram para $S$. aureus contagem de $2,5 \times 10^{6} \mathrm{UFC} / \mathrm{mL}$ para o queijo muçarela $\mathrm{e}$ $6,0 \times 10^{1} \mathrm{UFC} / \mathrm{mL}$ para o minas-padrão; enquanto para coliformes a $45^{\circ} \mathrm{C}$ a contagem foi superior a $2,4 \times 10^{2} \mathrm{UFC} / \mathrm{mL}$ em ambos. Os autores verificaram que existe deficiência das boas práticas utilizadas pelos produtores dos queijos e que muitos não utilizam a pasteurização do leite para produção do queijo.

A presença de coliformes termotolerantes encontrados neste trabalho sugere que se deve controlar a produção do queijo coalho, desde a utilização de matéria-prima com qualidade microbiológica e, principalmente, empregandose as boas práticas de fabricação, tendo em vista que as principais causas de contaminação por esses micro-organismos estão relacionadas à higiene tanto no processamento quanto do manipulador.

Os resultados da avaliação sensorial de preferência por ordenação das formulações A sabor morango, B - sabor caju, C - sabor goiaba, D - sabor graviola, E - sabor acerola com cenoura, e F - sabor abacaxi com hortelã estão 
apresentados na Tab. 2 e na Fig. 1. Observa-se, pela ordem crescente de valores, preferência pelas bebidas D, A, C, B, F e E (Tab. 2). Entre as preferências pelas formulações, verificou-se diferença significativa $(\mathrm{P}<0,05)$ quando se compararam as formulações D e A com B, F e E, sendo perceptível, portanto, que as preferidas foram as formulações sem hortaliça.
A formulação D (Fig. 1) ficou na primeira posição, com frequência de $17 \%$ de indicações para o primeiro lugar, seguida pela formulação A, com $18 \%$ de indicações para o segundo lugar; na terceira está a formulação $\mathrm{C}$, com $16 \%$ de indicações para o terceiro lugar. As formulações $\mathrm{F}$ e E obtiveram as maiores frequências, $14 \%$ e $20 \%$, para as indicações de quinto e sexto lugares, respectivamente.

Tabela 2. Resultados da avaliação sensorial de preferência segundo a formulação de bebida

\begin{tabular}{lllllll}
\hline Formulação & $\mathrm{A}$ & $\mathrm{B}$ & $\mathrm{C}$ & $\mathrm{D}$ & $\mathrm{E}$ & $\mathrm{F}$ \\
\hline Total (Soma) & $78 \mathrm{bc}$ & $108 \mathrm{~b}$ & $88 \mathrm{bc}$ & $66 \mathrm{c}$ & $163 \mathrm{a}$ & $118 \mathrm{~b}$ \\
\hline
\end{tabular}

Letras iguais na horizontal não diferem significativamente ao nível de 5\% de significância. $\mathrm{A}=$ morango; $\mathrm{B}=$ caju; $\mathrm{C}=$ goiaba; $\mathrm{D}=$ graviola; $\mathrm{E}=$ acerola + cenoura; $\mathrm{F}=$ abacaxi + hortelã.

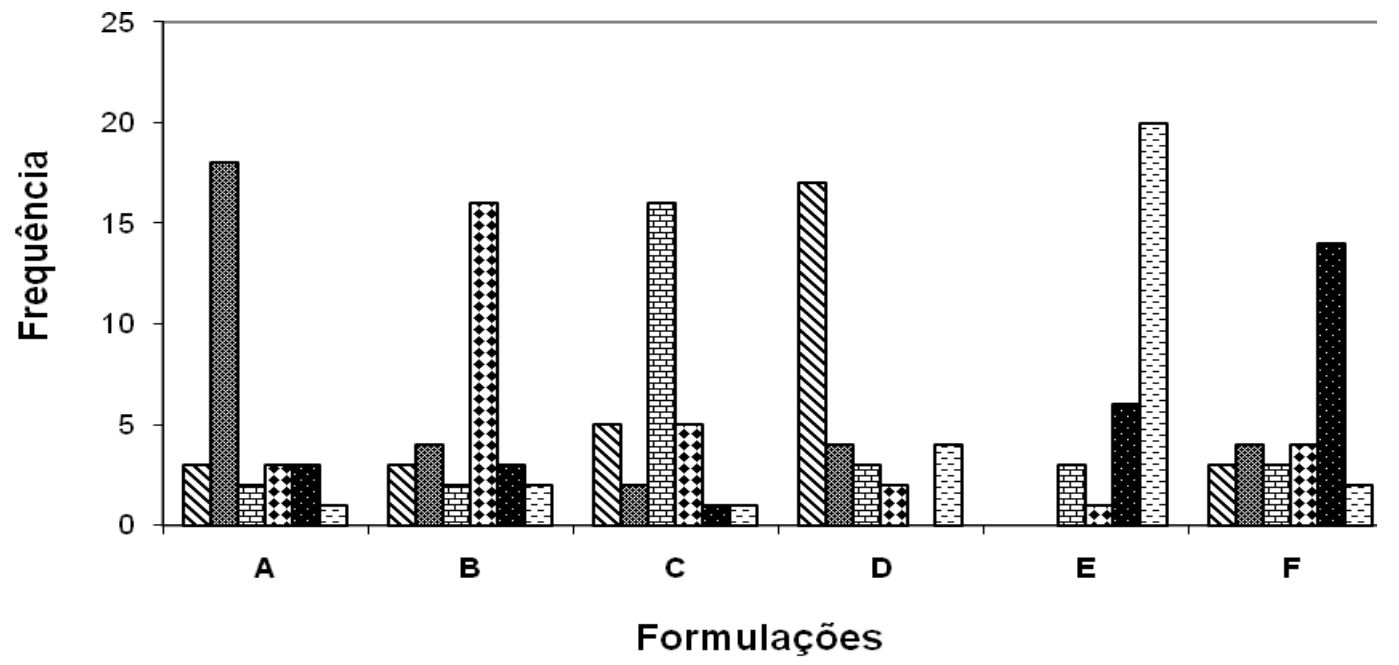

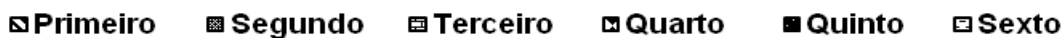

Figura 1. Frequência da avaliação sensorial de preferência segundo a formulação de bebida.

Pretendeu-se com as formulações utilizar a máxima quantidade de soro visando aumentar a possibilidade de seu aproveitamento e preparar bebidas de forma a apresentarem-se com o sabor agradável de fruta ou hortaliça, independentemente da consistência obtida e com o sabor de soro imperceptível, uma vez que este não é agradável ao paladar pela sua composição rica em minerais (Siqueira et al., 2002).

Na Fig. 2, observa-se que, ao analisar a primeira componente principal (PC1) que reproduz 97,7\% das informações, as amostras A e D estão com escores negativos, sendo, portanto, melhor representadas pelos atributos sensoriais aparência, cor, sabor e qualidade global, resultado confirmado pelas maiores e significativas $(\mathrm{P}<0,05)$ notas obtidas nestes atributos (Tab. 3). Com relação à segunda componente principal (PC2), que representa 2,0\% das informações, observa-se que a amostra C apresenta escore positivo, ou seja, foi caracterizada pelo atributo odor, confirmado pela maior e significativa nota $(\mathrm{P}<0,05)$ neste atributo. Isto pode ser explicado pelo odor mais perceptível do fruto goiaba, quando comparado às demais frutas utilizadas. 


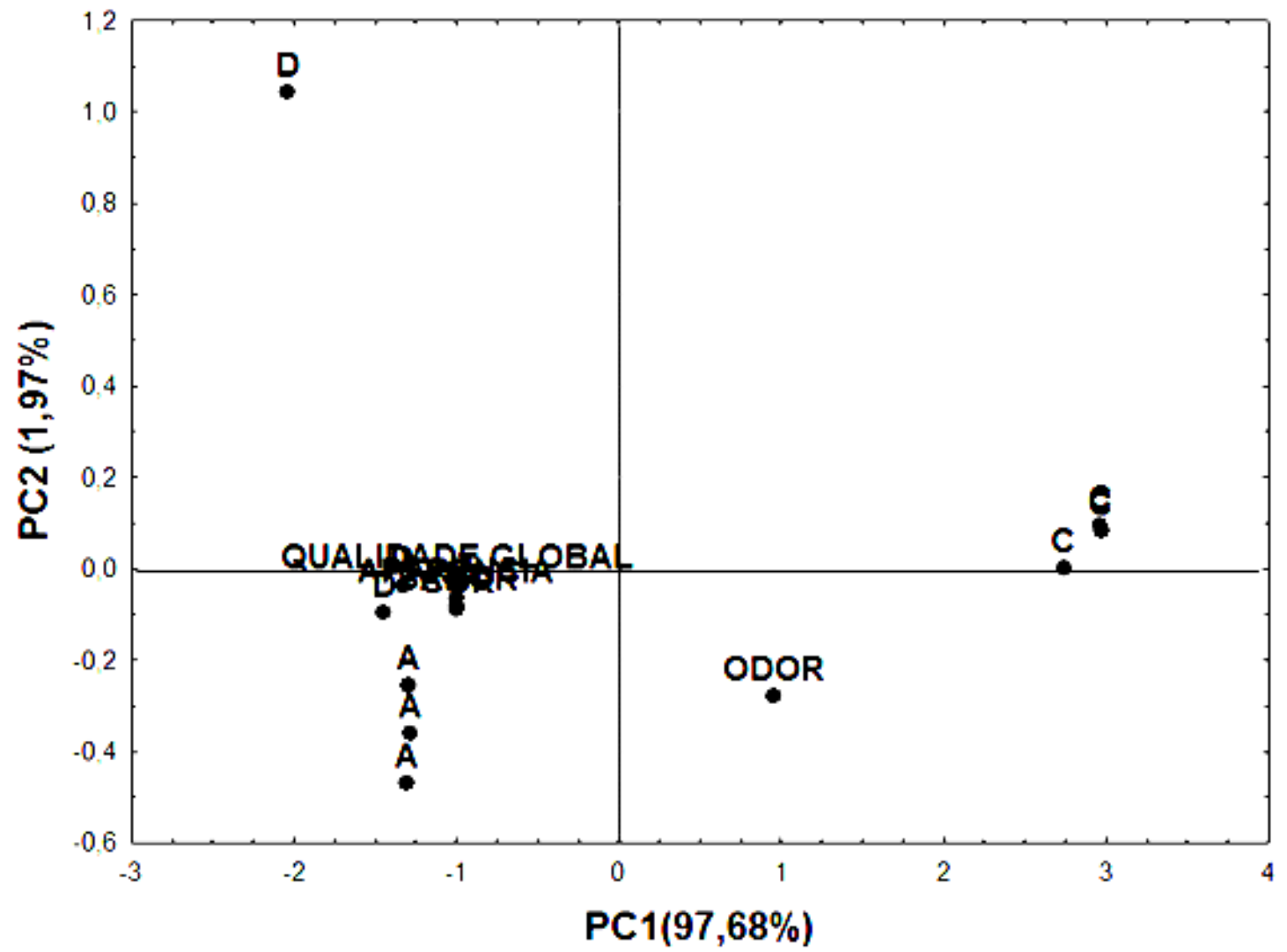

Figura 2. Projeção bidimensional de análise de componentes principais dos termos descritores das três bebidas preferidas - A: morango; C: goiaba; e D: graviola.

Tabela 3. Média obtida no teste de aceitação e índices de aceitabilidade de três bebidas preferidas

\begin{tabular}{ccccccc}
\hline Atributo & A & IA (\%) & C & IA (\%) & D & IA (\%) \\
\hline Aparência & $7,17 \pm 1,40 \mathrm{a}$ & 79,66 & $6,25 \pm 1,75 \mathrm{~b}$ & 69,44 & $7,37 \pm 1,09 \mathrm{a}$ & 81,88 \\
Cor & $7,17 \pm 1,58 \mathrm{a}$ & 79,66 & $6,12 \pm 1,93 \mathrm{~b}$ & 68 & $7,42 \pm 1,35 \mathrm{a}$ & 82,44 \\
Odor & $6,62 \pm 1,74 \mathrm{~b}$ & 73,55 & $7,83 \pm 1,67 \mathrm{a}$ & 87 & $5,58 \pm 2,22 \mathrm{~b}$ & 72 \\
Sabor & $6,87 \pm 1,30 \mathrm{a}$ & 76,33 & $5,42 \pm 2,66 \mathrm{~b}$ & 60,22 & $7,12 \pm 1,54 \mathrm{a}$ & 79,11 \\
Qualidade & $6,75 \pm 1,48 \mathrm{a}$ & 75 & $5,79 \pm 2,22 \mathrm{~b}$ & 64,33 & $7,29 \pm 0,95 \mathrm{a}$ & 81 \\
Global & & & & & &
\end{tabular}

Medias na linha acompanhada de letras distintas diferem entre si, a 5\% de significância, pelo teste de Duncan. A: morango; C: goiaba; D: graviola. IA: índice de aceitabilidade.

Os resultados do teste de aceitação das bebidas preferidas e os respectivos índices de aceitabilidade (IA) estão apresentados na Tab. 3. A formulação D (sabor graviola) obteve as melhores notas quando comparada com as formulações A e C. A bebida sabor graviola apresentou-se como a formulação preferida pelo sabor mais evidente da fruta, aparência agradável, cor semelhante ao do suco da fruta, fazendo com que a sua qualidade global obtivesse a maior nota quando comparada às demais. Para que o produto seja considerado como aceito, em termos de suas propriedades sensoriais, é necessário que este alcance índice de aceitabilidade de, no mínimo, 70\% (Teixeira et al., 1987), e a bebida sabor graviola apresentou os maiores valores, com IA superior ao mínimo estabelecido para os atributos avaliados, exceto para o odor.

A maior proporção de soro na bebida não foi responsável pela diminuição da preferência dos provadores na presente pesquisa, pois as bebidas sabor graviola, goiaba e caju, com as mesmas 


\section{Guedes et al.}

concentrações de soro, na proporção de $65 \%$, colocaram-se em primeiro, terceiro e quarto lugares, respectivamente. Ainda, comparando o primeiro e o último lugar, a bebida preferida apresentava-se com maior quantidade de soro $(65 \%)$ se comparada à escolhida em sexto lugar (45\%). Isto demonstra a importância do tipo de fruto a ser usado na elaboração de bebida com soro lácteo e as proporções utilizadas entre o vegetal e o soro. Santos et al. (2008), ao avaliarem a influência da concentração de soro na aceitação sensorial de bebida láctea fermentada com polpa de manga, observaram que os maiores teores de soro resultaram em menores notas entre as amostras analisadas, com escores próximos ao termo hedônico "indiferente".

O resultado da análise sensorial das bebidas sabor morango, caju e graviola, está apresentado na Fig. 3. A formulação A apresentou escore médio próximo ao termo hedônico gostei moderadamente para cor e gostei ligeiramente para os outros atributos, tendo boa aceitação pelos provadores. A formulação $\mathrm{C}$, que apresenta $65 \%$ de soro em sua formulação, apresentou escore médio próximo ao termo hedônico gostei ligeiramente para o atributo aparência e cor; para o atributo sabor e qualidade global, apresentou escore médio próximo a não gostei nem desgostei, destacando-se no odor, escore médio próximo a gostei moderadamente, o que pode ser explicado em razão de o odor da fruta goiaba ser bem mais forte que as demais pesquisadas. A formulação D, com $65 \%$ de soro em sua formulação, obteve os melhores escores médios próximos ao termo hedônico gostei moderadamente para todos os atributos, com exceção do atributo odor, possivelmente pela maior evidência do odor do soro lácteo. Esta formulação apresentou diferença $(\mathrm{P}<0,05) \mathrm{em}$ relação à bebida sabor goiaba (Tab. 3$)$.

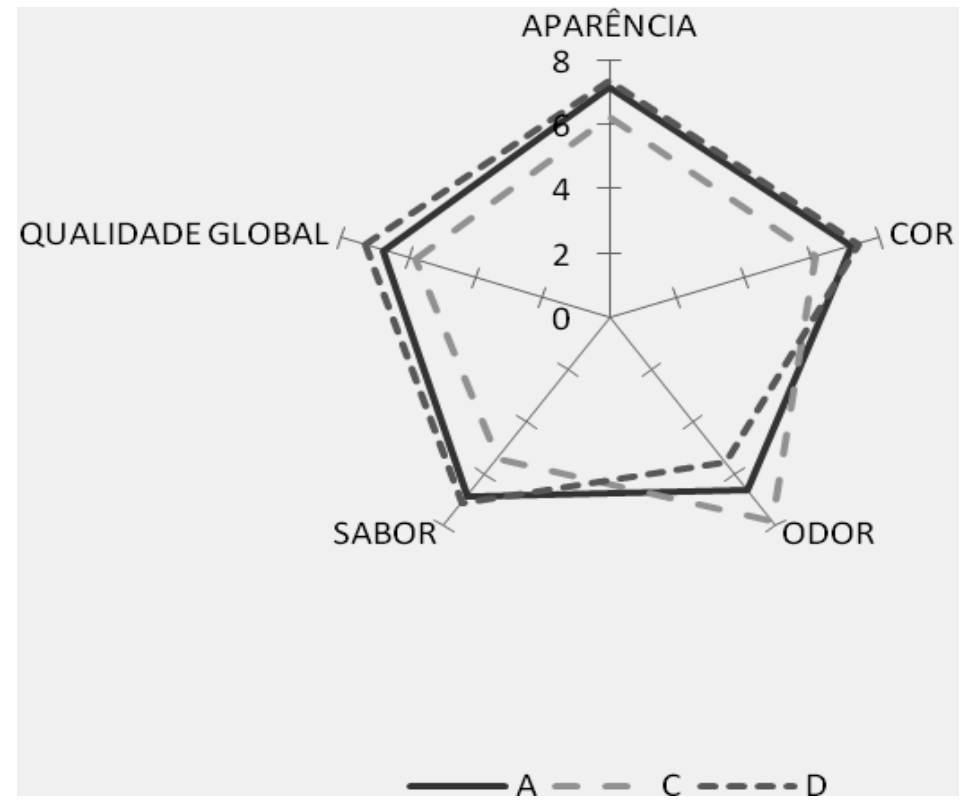

Figura 3. Resultado da análise sensorial das três bebidas preferidas - A: morango; C: goiaba; e D: graviola.

Menezes (2011), ao desenvolver bebida láctea fermentada à base de soro de leite e polpa de cajá, observou que as formulações com 20, 30 e $40 \%$ de soro em substituição parcial ao leite, totalizando uma base láctea que variou de 75 a $85 \%$, apresentaram resultados satisfatórios, obtendo-se índice de aceitabilidade maior que $70 \%$ para as formulações desenvolvidas, resultado também constatado neste trabalho.

Com base nas médias das notas para a aceitabilidade e o cálculo do IA, pode-se verificar que a formulação $D$ foi a bebida preferida e a mais aceita quanto aos atributos 
sensoriais, sendo, portanto, submetida às análises físico-químicas. Esta bebida caracterizou-se pelos valores médios de $82,54 \mathrm{~g} / 100 \mathrm{~g}$ de umidade; $\mathrm{pH}$ de 4,1; acidez titulável de 4,19g/100g; 0,7g/100g de lipídeo; 0,67g/100g de proteína e $0,35 \mathrm{~g} / 100 \mathrm{~g}$ de cinzas.

O aumento no teor de umidade de uma bebida láctea é explicado pela maior quantidade de substituição de leite pelo soro, o que diminui a quantidade de sólidos totais e aumenta a água na formulação. Santos et al. (2008) não observaram diferença significativa para o teor de umidade, que variou entre 75,9 e 78,6\%, quando utilizaram 20, 40 e $60 \%$ de soro lácteo em substituição parcial ao leite, totalizando uma base láctea de $74,7 \%$. Esses resultados são mais baixos que os obtidos na presente pesquisa, o que é explicado pelo maior teor de soro utilizado na bebida sabor graviola $(65 \%)$ da presente pesquisa.

A acidez exerce grande influência sobre os atributos de qualidade dos produtos lácteos e é um dos fatores que limita sua aceitação. A baixa acidez das bebidas lácteas favorece sua aceitabilidade pelos consumidores, além de ter importância no aspecto visual do produto final durante a armazenagem sob refrigeração. Os resultados de $\mathrm{pH}$ e acidez titulável são semelhantes aos encontrados por Oliveira et al. (2006), que obtiveram resultados entre 4,1 e 4,2 e concluíram que esses valores não descaracterizam o produto por apresentarem valores semelhantes aos de bebida láctea que, em média, é de 4,5.

$\mathrm{Na}$ formulação D, os teores lipídicos foram mais altos que os encontrados por Cruz et al. (2009), que obtiveram resultados entre 0,12 e $0,14 \%$, ao elaborarem bebidas à base de soro de queijomanteiga e suco de acerola. Isto pode ser explicado pelas diferenças nas composições químicas dos soros de queijo utilizados no estudo. Apesar de a gordura do leite ser um ingrediente importante para os derivados lácteos, o seu consumo em alta escala vem sendo bastante enfatizado pelo aumento dos casos de obesidade, do colesterol sanguíneo e de doenças coronarianas na população brasileira, por isso torna-se importante o consumo de bebidas lácteas com baixo teor lipídico.

Cunha et al. (2009) encontraram teores proteicos que variaram de 1,7 a $2,2 \%$ na formulação de bebidas, ao utilizarem diferentes concentrações de soro lácteo em substituição parcial ao leite. Valores mais baixos foram encontrados pela presente pesquisa por ter utilizado somente o soro de queijo na bebida sabor graviola.

O teor de cinzas obtido na presente pesquisa é menor que o encontrado por Cunha et al. (2008), que obtiveram $0,65 \%$, ao desenvolverem uma bebida láctea elaborada com $70 \%$ de leite e $30 \%$ de soro de queijo minas-frescal, o que pode ser explicado pela utilização de leite na elaboração da bebida desenvolvida por esses autores.

Estes resultados demonstram que a utilização do soro de queijo coalho é viável sensorial e tecnologicamente na formulação de bebidas com frutas, levando ao aproveitamento de um potencial agente poluidor e à criação de novos subprodutos lácteos, além de que a proporção de soro adequado para uma bebida depende do tipo da fruta e hortaliça, desta forma foi possível elaborar bebidas com diferentes proporções de soro lácteo.

\section{CONCLUSÕES}

O soro é viável no aproveitamento de bebidas com frutas. Seu teor não influenciou na aceitação das bebidas formuladas, e, entre as frutas utilizadas, a graviola foi a preferida. A bebida sabor graviola apresentou baixo teor lipídico, contém proteínas e minerais, desta forma pode ser indicada na construção de cardápios a grupos que necessitam de alimentos com essas características.

\section{AGRADECIMENTO}

À Fundação de Amparo à Ciência e Tecnologia do Estado de Pernambuco, pelo auxílio financeiro a esta pesquisa.

\section{REFERÊNCIAS}

ANDRADE, R.L.P.; MARTINS, J.F.P. Influência da adição da fécula de batata-doce (Ipomoea batatas L.) sobre a viscosidade do permeado de soro de queijo. Cienc. Tecnol. Aliment., v.22, p.249-253, 2002.

ASSOCIATION of Official Analytical Chemists. Official Methods of Analysis. Washington, 2002. 
BRASIL. Agência Nacional de Vigilância Sanitária. RDC n 12, de 02 de janeiro de 2001. Aprovar o Regulamento Técnico sobre Padrões Microbiológicos para Alimentos. Brasília, DF, 2001.

CAPITANI, C.D.; PACHECO, M.T.B.; GUMERATO, H.F. et al. Recuperação de proteínas do soro de leite por meio de coacervação com polissacarídeo. Pesq. Agropec. Bras., v.40, p.1123-1128, 2005.

CUNHA, T.M.; ILHA, E.C.; AMBONI, R.D.M.C. et al. A influência do uso de soro de queijo e bactérias probióticas nas propriedades de bebidas lácteas fermentadas. Braz. J. Food Technol., v.12, p.23-33, 2009.

CUNHA, T.M.; CASTRO, F.P.; BARRETO, P.L.M. et al. Avaliação físico-química, microbiológica e reológica de bebida láctea e leite fermentado adicionados de probióticos. Semina Cienc. Agrar., v.29, p.103-116, 2008.

CRUZ, A.G.; SANT'ANA, A.S.; MACCHIONE, M.M. et al. Milk drink using whey butter cheese (queijo manteiga) and juice as a potential source of vitamin C. Food Bioprocess Technol., v.2, p.368-373, 2009.

DUTCOSKY, S.D. Análise sensorial de alimentos. Curitiba: Ed. DA Champagnat, 1996. $123 \mathrm{p}$.

INSTITUTO brasileiro de geografia e estatística (IBGE). Produção da Pecuária Municipal. Rio de Janeiro, v.37, p.1-55, 2009.

MAPA. Assessoria de Gestão Estratégica. Projeções do Agronegócio Brasileiro. Disponível em: <http://www.agricultura.gov.br>. Acessado em: 27 mar. 2011.

MENEZES, A.C.S. Desenvolvimento de bebida láctea fermentada à base de soro de leite e polpa de cajá (Spondias Mombin L.) com potencial atividade probiótica. 2011. 106f. Dissertação (Mestrado em Ciência e Tecnologia de Alimentos) Universidade Federal Rural de Pernambuco, Recife.

MONTEIRO, C.L.B. Técnicas de avaliação sensorial. 2.ed. Curitiba: CEPPA - UFPR, 1984. $101 \mathrm{p}$.
OLIVEIRA, V.M.; CORTEZ, M.A.S.; FREITAS, M.Q. et al. Avaliação sensorial de bebida láctea fermentada com diferentes concentrações de soro de queijo, enriquecida com ferro. Rev. Bras. Cienc. Vet., v.13, p.67-70, 2006.

PINTADO, M.E. Review: technology, chemistry and microbiology of whey cheeses. Food Sci. Technol. Int., v.7, p.105-116, 2001.

SANTOS, C.T.; COSTA, A.R.; FONTAN, G.C.R. et al. Influência da concentração de soro na aceitação sensorial de bebida láctea fermentada com polpa de manga. Alim. Nutr., v.19, p.55-60, 2008.

SANTOS, J.P.V.; FERREIRA, C.L.L. Alternativas para o aproveitamento de soro de queijo nos pequenos e médios laticínios. Rev. Inst. Lat. Candido Tostes, v.56, p.44-50, 2001.

SIQUEIRA, I.M.C.; SOUZA, M.R.; CERQUEIRA, M.M.O.P. et al. Importância e utilização dos derivados de soro de queijo. Hig. Aliment., v.16, p.31-35, 2002.

STATSOFT. 1997. Statistic for windows 5.1. CD ROM. Tulsa, Statsoft Inc.

TEIXEIRA E.; MEINERT, E.M.; BARBETTA, P.A. Análise sensorial de alimentos. Florianópolis: UFSC, 1987. 180p

TEIXEIRA, L.V.; FONSECA, L.M.; MENEZES, L.D.M. Avaliação da qualidade do soro de queijos minas padrão e mozarela produzidos em quatro regiões do estado de Minas Gerais. Arq. Bras. Med. Vet. Zootec., v.59, p.264-267, 2007.

TEIXEIRA, V.L.; FONSECA, L.M. Perfil físicoquímico do soro de queijos mozarela e minaspadrão produzidos em várias regiões do estado de Minas Gerais. Arq. Bras. Med. Vet. Zootec., v.60, p.243-250, 2008.

VANDERZANT C.; SPLITTSTOESSER D.F. Compendium of methods for the microbiological examination of foods. 3.ed. Washington American Public Health Association, 1992. 1219p. 